\title{
Toxicological Evaluation of Some Essential Oils Obtained from Selected Romania Lamiaceae Species in Complex with Hydroxypropyl - gamma-cyclodextrin
}

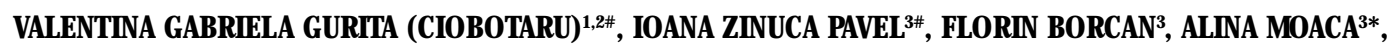 \\ CORINA DANCIU ${ }^{3}$, ZORITA DIACONEASA ${ }^{4}$, ILINCA IMBREA ${ }^{1}$, DALIBORCA VLAD ${ }^{5 *}$, VICTOR DUMITRASCU5, GEORGETA POP ${ }^{1}$ \\ ${ }^{1}$ Faculty of Agriculture, Banat's University of Agricultural Sciences and Veterinary Medicine King Michael I of Romania, 119, \\ Calea Aradului, 300645, Timisoara, Romania \\ 2Municipal Clinical Emergency Hospital, 5, Gh. Dima, 300079, Timisoara, Romania \\ ${ }^{3}$ Faculty of Pharmacy, University of Medicine and Pharmacy Victor Babes, 2 Eftimie Murgu Sq., 300041, Timisoara, Romania \\ ${ }^{4}$ Department of Food Science, University of Agricultural Sciences and Veterinary Medicine of Cluj-Napoca, 3-5 Calea Mãnãotur, \\ 400372, Cluj-Napoca, Romania. \\ ${ }^{5}$ Faculty of Medicine, University of Medicine and Pharmacy Victor Babes, 2 Eftimie Murgu Sq., 300041, Timisoara, Romania
}

\begin{abstract}
Medicinal plants are highly investigated due to their multiple effects in human health. In the last two decades, plants belonging to Lamiaceae family have emerged as an important source of compounds with beneficial effects in various pathologies. Many species of the Lamiaceae family have a high volatile oil content which can be found in different parts of the plant. Some representative examples include Lavandula spp. Salvia spp. and Mentha spp. which are species with essential oils studied for antioxidant, antimicrobial and antitumor effects. The aim of this study was to evaluate the effect of six essential oils at skin level before and after encapsulation in hydroxypropyl-gamma-cyclodextrins. Results indicated that regardless of the tested form, the samples did not display an irritating or toxic effect at skin level, suggesting that the essential oils can be used in different formulations for topical application.
\end{abstract}

Key words: essential oils, Lamiaceae, hydroxypropyl-gamma-cyclodextrins, mexametry, corneometry, tewametry

Plants from Lamiaceae family are widely used nowadays because of their multiple beneficial effects including antitumor, antimicrobial, anti-inflammatory, analgesic potential etc [1-3]. Many species from this family are known to produce essential oils (EO) used in both medical field as well as in the in the cosmetics and food industry [1]. EO are reported to possess a mixture of active compounds, the most numerous being terpenoides and their oxygenated derivatives. The chemical composition of EO can be influenced by the geographic location, the cultivation method, the storage and the extraction method used [4]. EO are produced by plants as a protection against parasites and insects. They can also provoke adverse or toxic effect on humans especially because rigorous tests to determine the safety of EO are not well established [4].

Lavender spp. EO are used for their potent antibacterial effects. They are recommended in vaginal and sinus infections, to reduce stress, in burns and skin problems and to stimulate the immunity [5]. Furthermore, according to Cavanagh et al., lavender EO is used in numerous dermatological conditions such as dermatitis, eczema and psoriasis, but they also pointed that there are studies showing that exposure to lavender oil can produce dermatitis [6].

Beside the medical employment, EO obtained from Salvia sclarea $\mathrm{L}$. are used in both the cosmetics and food industry. It is unanimously accepted that plant origins and extraction method can influence the chemical composition of the EO [1]. Kuzma et al indicated that Salvia sclarea EO are used for various effects such as anti-inflammatory, antioxidant, antibacterial and analgesic [7].

Menthae spp. EO are used in both traditional and modern medicine in a consistent way for the gastrointestinal and respiratory tract for the analgesic, decongestant and antispastic effects [4]. It is not to be neglected that depending on the administration method, Menthae spp. EO can induce adverse effects such as allergic reactions, nausea and flushing [4]. The main components in Menthae piperita L. EO are menthol and menthone but other components like pulegone, and menthofuran can also be present [8]. Nair B. indicated that following intradermal administration of $0.05 \mathrm{~mL}$ of peppermint oil in rabbits, moderate (presence of lymphocytes, plasma cell and polymorphonuclear leukocytes) or severe reactions (necrosis) were noticed. He concluded that pulegone concentration in various peppermint formulation should not exceed $1 \%$ [8]

Cyclodextrins (CD) are commonly used as excipients due to the properties to form inclusion complexes with an increasing number of molecules. Generally this approach is conducted in order to augment the water solubility of selected compounds. CDs are often used in drug delivery systems due to their safety and stability [9]. Gammacyclodextrins are frequently used in drug delivery because they permit the inclusion of large molecules [10].

The present study was aimed to provide a toxicological evaluation of some essential oils obtained from Lavandula spp. Salvia spp. and Mentha spp, belonging to the Lamiaceae family and harvested from Romania and also to establish their effects at skin level after encapsulation in hydroxypropyl-gamma-cyclodextrins.

\section{Experimental part}

Materials and method

Chemicals and reagents

Hydroxypropyl-gamma-cyclodextrin was purchased from Cyclolab (Budapest, Hungary) and sodium lauryl 
sulfate (SLS) was acquired from Chemical Company SA, lasi, Romania.

\section{Harvesting of the plants}

The plants were harvested in the period july - august 2013 , during the flowering period at noon time. The material obtained was processed in the same day. The plants were identified and deposited in the Herbarium Department of Medicinal Plants, Banat's University of Agricultural Science and Veterinary Medicine Timisoara. A voucher specimen was assigned to each plant.

Lavandula angustifolia Mill. (sample S1) - was collected from Timisoara Young Naturalists Resort (voucher specimen code VSNH.BUASTM - 85); Salvia officinalis L. (sample S2) -collected from Madrid experimental field, Spain (voucher specimen code VSNH.BUASTM -98); Lavandula hybrida Balb. ex Ging (sample S3) - collected from Timisoara Young Naturalists Resort (voucher specimen code VSNH.BUASTM -86); Salvia sclarea L. (sample S4) - collected from Timisoara Young Naturalists Resort (voucher specimen code VSNH.BUASTM - 97); Mentha smithiana L. (sample S5) - collected from Timisoara Young Naturalists Resort (voucher specimen code VSNH.BUASTM - 90); Mentha piperita L. (sample S6) - collected from Timisoara Young Naturalists Resort (voucher specimen code VSNH.BUASTM -89).

\section{Essential oils extraction method}

The aerial parts of the plants (stem, leaves and plant flowers) have been distilled in order to obtain the essential oils. The plant material was placed in the special glass flask above the boiling water flask. At boiling time, the steam entered in contact with the mass of vegetal material and destroied the glands than encompass the oil, volatilized the oil and then was mixed with it. Hence, the steam containing the volatile oil molecules was drawn through the pipe to the cooling column. The water and oil steam condensated and passed into the separator. For each distillation series, about 100-150 $\mathrm{g}$ of dried vegetal material was placed in the recipient over the boiling water. The plant material was kept to distill about 25 min after the first steam passed through the dry herb. Then, the water was separated from the oil, the latter remaining above the water due to density differences. The extracted essential oil was stored at $4^{\circ} \mathrm{C}$ in brown bottles until use.

For all studied samples, the amount of essential oil obtained from $100 \mathrm{~g}$ of dried herb was determined and the drying yield was calculated. The drying yield is the total amount of dry plant remaining in relation to the initial quantity of fresh plant weighed immediately after harvesting and conditioning.

\section{Cyclodextrin incorporation}

The protocol used to obtain the cyclodetrins' complex, known as the kneading procedure, was already described in our previous scientific papers [10-12]: the active substance and hydroxypropyl-gamma-cyclodextrin - molar ratio 1:2 - were triturated with a mortar and a pestle, followed by kneading with a $50 \%$ ethanol solution until an important part of the solvent was evaporated. In the last step, the product was dried at room temperature for $24 \mathrm{~h}$ and then at $105^{\circ} \mathrm{C}$ in a laboratory oven for several hours, until constant weight. The obtained product was pulverized and sieved.

\section{Non-Invasive Skin Measurements}

The volunteers were: 9 healthy human subjects ( 2 males and 7 females), without skin lesions, between 19 and 23 years of age. Measurements were performed with a Curage-Khazaka (Germany) multisone (MPA6) multisone system (MPA6) equipped with a Tewameter ${ }^{\circledR}$ TM300 probe, a Mexameter ${ }^{\circledR}$ MX18 probe and a Corneometer ${ }^{\circledR}$ CM825 probe. All requirements of Courage-Khazaka (Germany) were met: room temperature $\left(24 \pm 1^{\circ} \mathrm{C}\right)$; moisture ( $50 \pm 3 \%$ ); all measurements were made by the same operator. Values are expressed as an average of at least 3 measurements +/- standard errors; differences were calculated and displayed graphically. A $2 \%$ sodium lauryl sulfate sample solution, known as skin irritant, was used as a control using the same procedure.

\section{Statistical analysis}

The results were expressed as mean \pm standard deviation. The comparison between groups was performed using the One-way ANOVA test (ns for $P>0.05$, * for $P \leq$ 0.05 , *** for $\mathrm{P} \leq 0.01$, *** for $\mathrm{P} \leq 0.001$ and $* * * *$ for $\mathrm{P} \leq$ 0.0001).

\section{Results and discussions}

Quantification of the essential oils obtained

Tabel 1 presents the amount of essential oils obtained from $100 \mathrm{~g}$ of dried aerial parts of the aforementioned species. The highest quantity was recorded for Lavandula hybrida Balb. ex Ging (1.54\% essential oil/100g herba), whereas the lowest amount was found for Salvia officinalis L. ( $0.41 \%$ essential oil $/ 100 \mathrm{~g}$ herba).

Table 1

THE QUANTITY OF ESSENTIAL OILS OBTAINED FROM $100 \mathrm{~g}$ OF HERBA (\%)

\begin{tabular}{|l|l|c|}
\hline No. & Specia & $\begin{array}{l}\text { The quantity of oil } \\
\text { obtained from } \mathbf{1 0 0} \mathbf{g} \\
\text { of herba (\%) }\end{array}$ \\
\hline S1 & Lavanaula angustifolia Mill. & 1.15 \\
\hline S2 & Salvia officinalis L. & 0.41 \\
\hline S3 & Lavanaila hybrida Balb. ex Ging & 1.54 \\
\hline S4 & Salvia sclarea L. & 1.01 \\
\hline S5 & Mentha smithiana L. & 0.56 \\
\hline S6 & Mentha piperita L. & 1.11 \\
\hline
\end{tabular}

\section{Evaluation of the drying yield}

In table 2 is represented the total amount of dry vegetal material remaining in relation to the initial quantity of fresh vegetal material weighed immediately after harvesting and conditioning. The highest drying yield was obtained for Lavandula angustifolia Mill. (39.2\%).

Table 2

THE DRYING YIELD OF THE ESSENTIAL OILS

\begin{tabular}{|l|l|c|}
\hline No. & \multicolumn{1}{|c|}{ Plant used } & Drying yield (\%) \\
\hline 1. & Lavandula angustifolia Mill. (S1) & 39.2 \\
\hline 2. & Salvia officinalis L. (S2) & 31.88 \\
\hline 3. & Lavandula hybrida Balb. ex Ging (S3) & 35.6 \\
\hline 4. & Salvia sclarea L. (S4) & 31.88 \\
\hline 5. & Mentha smithiana L. (S5) & 34.2 \\
\hline 6. & Mentha piperita L. (S6) & 30.1 \\
\hline
\end{tabular}

\section{Non-Invasive Skin Measurement}

The effect of the six essential oils was determined before and after encapsulation in hydroxypropyl-gammacyclodextrins. The samples were topical applied on healthy volunteers. Data were compared with a $2 \%$ sodium lauryl sulfate sample solution (SLS), known to be a skin irritant. 

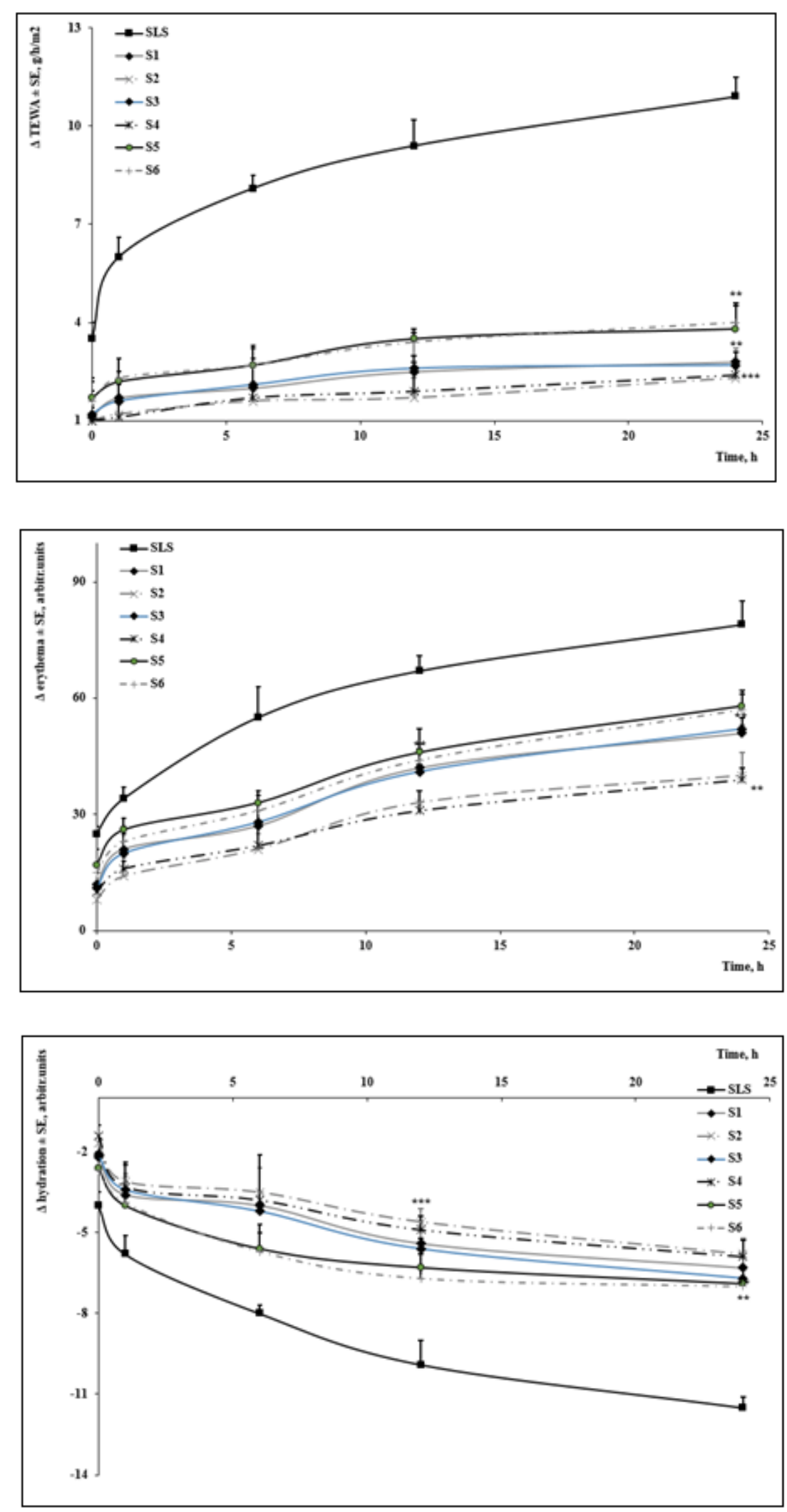

Fig. 1. Transdermal water loss for nonencapsulated essential oils

Fig. 2. Erythema evolution for nonencapsulated essential oils
Fig. 3. Skin hydration for non-encapsulated essential oils
Figures 1 - 3 describe the effect of the non-encapsulated essential oils on skin parameters (transdermal water loss, erythema evolution and skin hydration). In Figure 1 is represented the effect of the EO on the transdermal water loss (TEWL), which is considered to be a representative factor of skin barrier integrity [13]. Application of SLS solution induced a significant increase in TEWL value. Comparing the effects induced following EO application, it can be concluded that all EO induced lower values than the ones obtained with the irritant skin solution. Among the EO, the highest TEWL values were obtained for the
Menthae spp. (M. piperita and M. smithiana), whereas the lowest values were present for the Salvia spp. EO.

The erythema values can be correlated with the content of hemoglobin. As expected, application of SLS led to an increase of erythema values (Figure 2). Regarding the effect elicited by the EO, the highesterythema values were recorded for M. smithiana and M. piperita.

In Figure 3 is displayed the skin hydration level after application of the samples. This parameter shows the water content of the stratum corneum [13]. Our results showed a significant decrease in hydration after application 
of the SLS solution. All EO induced only a mild decrease in the hydration level as compared to the SLS solution, with Mentha spp. having the lowest values.

Figures 4-6 describe the modification produced at skin level after incorporation of the essential oils in hydroxypropyl-gamma-cyclodextrin (CD) (transdermal water loss, erythema evolution and skin hydration). The aforementioned parameters were also evaluated after encapsulation of the EO in CD and compared to the SLS solution and also to blank $C D$. Similar results were recorded for the TEWL values among the encapsulated EO and blank $\mathrm{CD}$ (Figure 4).
In Figure 5 is represented the erythema level after application of the encapsulated EO. No significant differences were exhibited between the encapsulated samples and blank CD, suggesting a good encapsulation of the EO. Furthermore, SLS solution provoked a significant increase of erythema level compared to the other samples, indicating that the samples do not induce irritating effects at skin level.

The water content of the stratum corneum was significantly improved in the case of encapsulated EO compared to SLS solution application (Figure 6), showing that this formulation do not alter skin hydration.
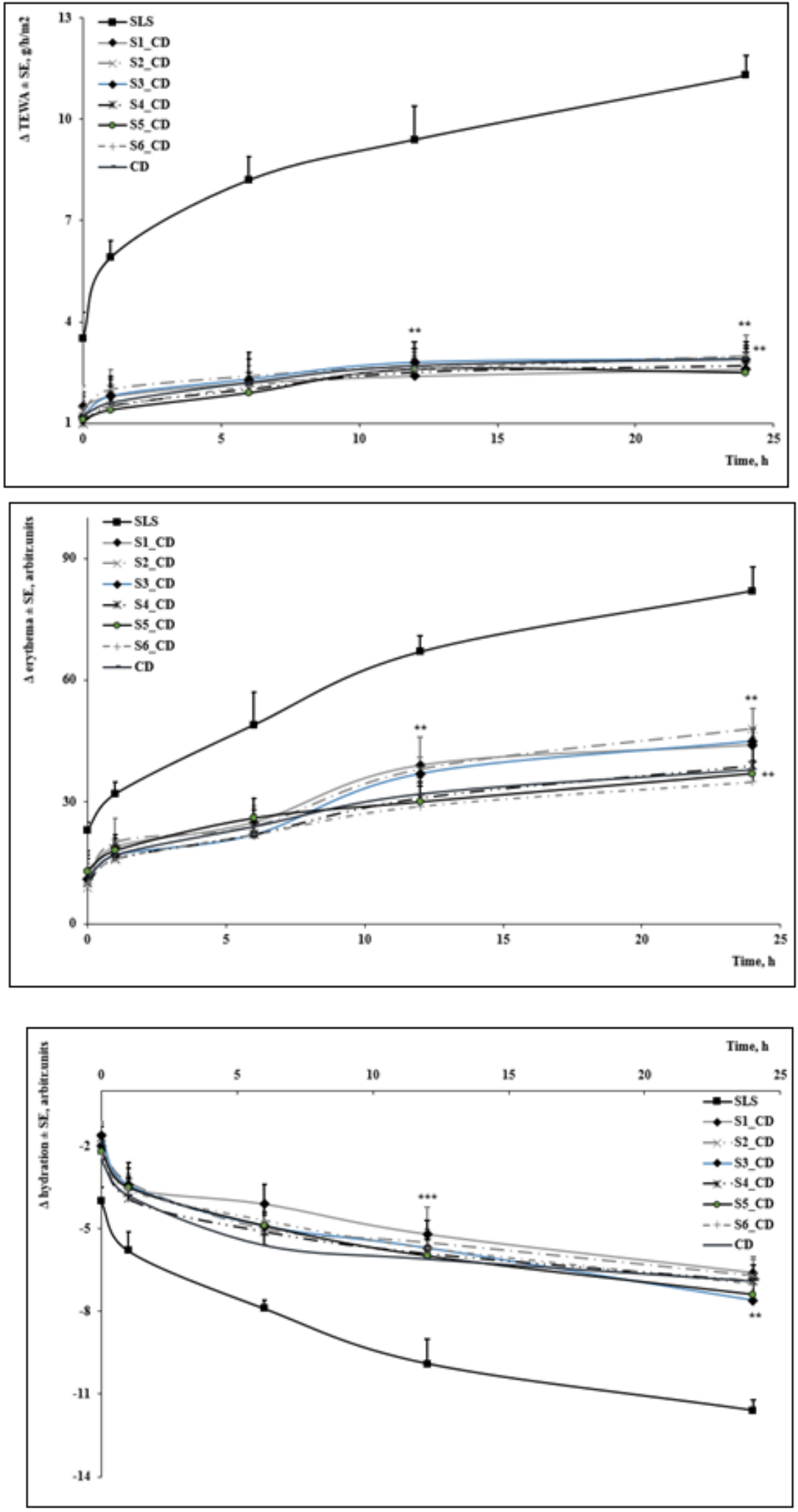

Fig. 4. Transdermal water loss for the essential oils encapsulated in hydroxypropylgamma-cyclodextrin
Fig. 5. Erythema evolution for the essential oils encapsulated in hydroxypropyl-gamma-cyclodextrin
Fig. 6. Skin hydration for the essential oils encapsulated in hydroxypropylgamma-cyclodextrin 
The physiological skin parameters (TEWL, erythema and skin hydration) did not show an irritant or toxic effect following application of the non-encapsulated or encapsulated EO. Furthemore, the results obtained for all the samples were significantly different than the ones obtained in the case of the sodium lauryl sulfate solution. However, it should be noted that the samples encapsulated in CD displayed a similar pattern of behavior, having similar results - this is an indication of good encapsulation of the EO (high encapsulation efficiency). In the case of nonencapsulated EO, there is a slight similarity between samples 1 and 3 (both from Lavandula spp.), 2 and 4 (both from Salvia spp.) and 5 and 6 (both from Mentha spp.). Only mild changes were recorded for the EO obtained from Menthae spp., compared to the other four samples, while the fewest changes at skin level were displayed in the case of Salvia officinalis and Salvia sclarea.

$C D$ encapsulation was performed due to their safety and stability as drug delivery systems [10]. In the present study, no changes at skin level were observed after application of encapsulated EO or blank CD, suggesting that this system is suitable for topic application. Previous studies indicated that $C D$ are adequate inclusion complexes for active compounds obtained from essential oils [14]. Menezes et al. indicated that (-)-linalool was successfully incorporated in $\beta$-cyclodextrin [14]. In a study conducted by Santos and coworkers it was shown that following inclusion of the sesquiterpene $\beta$-Caryophyllene in methyl- $\beta$-cyclodextrin, a significant improvement of biological properties were recorded [15].

\section{Conclusions}

Both pure as well as encapsulated tested oils have no significant irritating or toxic effects on skin level and can be considered safe for human application.

\section{References}

1. MAMADALIEVA, N., AKRAMOV, D., OVIDI, E., TIEZZI, A., NAHAR, L., AZIMOVA, S., SARKER, S.D., Medicines (Basel), 4, nr. 1, 2017, pii: E8;
2. URITU, C.M., MIHAI, C.T., STANCIU, G.D., DODI, G., ALEXASTRATULAT, T., LUCA, A., LEON-CONSTANTIN, M.M., STEFANESCU, R., BILD, V., MELNIC, S., TAMBA, B.I., Pain Res Manag., 2018, 2018, 7801543, p. 1;

3. WALLER, S.B., CLEFF, M.B., SERRA, E.F., SILVA, A.L., GOMES, A.D., DE MELLO, J.R., DE FARIA, R.O., MEIRELES, M.C., Microb Pathog., 104, 2017, p. 232;

4. STRINGARO, A., COLONE, M., ANGIOLELLA, L., Medicines (Basel)., 5, nr. 4, 2018, pii: 112;

5. ELSHAFIE, H.S., CAMELE, I., Biomed Res Int., 2017, 2017, ID 9268468 , p. 1;

6. CAVANAGH, H.M.A., WILKINSON, J .M., Phyther Res., 16, nr. 4, 2002, p. 301;

7. KUZMA, L., KALEMBA, D., ROZALSKI, M., ROZALSKA, B., WIÊCKOWSKA-SZAKIEL, M., KRAJEWSKA, U., WYSOKIÑSKA, H., Molecules, 14, nr. 4, 2009, p. 1438;

8. NAIR, B., Int J Toxicol., 20, nr. 3, 2001, p. 61;

9. SOICA, C., CORICOVAC, D., DEHELEAN, C., PINZARU, I., MIOC, M., DANCIU, C., FULIAS, A., PUIU, M., SITARU, C., Recent Pat Nanotechnol., 10, nr. 2, 2016, p. 128;

10. GALUSCAN, A., JUMANCA, D., BORCAN, F., SOICA, C., IONESCU, D., RUSU, L.C., CRAINICEANU, Z., Rev Chim (Bucharest)., 65, no. 2, 2014, p. 190;

11.DANCIU, C., SOICA, C., DEHELEAN, C., ZUPKO, I., CSANYI, E., PINZARU, I., Anal Cell Pathol (Amst)., 2015, 2015, ID 262930, p. 1;

12.ALUAS, M., SOICA, C., GYERESI, A., DEHELEAN, C., SIMON, S., Rev Chim (Bucharest), 58, no. 10, 2007, p. 891

13.DEHELEAN, C.A., SOICA, C., PINZARU, I., CORICOVAC, D., DANCIU, C., PAVEL, I., BORCAN, F., SPANDIDOS, D.A., TSATSAKIS, A.M., BADERCA, F., Food Chem Toxicol., 95, 2016, p. 149;

14.MENEZES, P.P., SERAFINI, M.R., QUINTANS-JUNIOR, L.J ., SILVA, G.F., OLIVEIRA, J.F., CARVALHO, F.M.S., SOUZA, J.C.C., MATOS, J.R., ALVES, P.B., MATOS, I.L., HADARUGA, D.I., ARAÚJO, A.A.S., J Therm Anal Calorim., 115, nr. 3, 2014, p. 2429;

15. SANTOS, P.S., SOUZA, L.K.M., ARAUJ O, T.S.L., MEDEIROS, J.V.R., NUNES, S.C.C., CARVALHO, R.A., PAIS, A.C.C., VEIGA, F.J.B., NUNES, L.C.C., FIGUEIRAS, A., ACS omega., 2, nr. 12, 2017, p. 9080;

Manuscript received: 15.09 .2019 